\title{
Der Bauernmaler
}

Jörg Nef

Korrespondenz:

Dr. med. Jörg Nef

Obere Weidegg 4

CH-9230 Flawil

\section{Vorwort}

Diese Geschichte ist nicht geeignet für Spital-CEOs, Gesundheitsökonomen, Gesundheitspolitiker, Medizin-Controller und andere Gesundheitsfunktionäre, welche die ärztlichen Leistungen vermarkten wollen wie in einem Supermarkt und die Spitäler zu gewinnorientierten Unternehmen pervertieren wollen, wenn möglich börsenkotiert.

\section{Ort und Zeit}

Bezirksspital in der Ostschweiz Anfang der 60er Jahre des vergangenen Jahrhunderts. Das Spital besteht aus zwei Gebäuden: einem Hauptbau und dem sogenannten «Abs» (Absonderungshaus für TuberkulosePatienten).

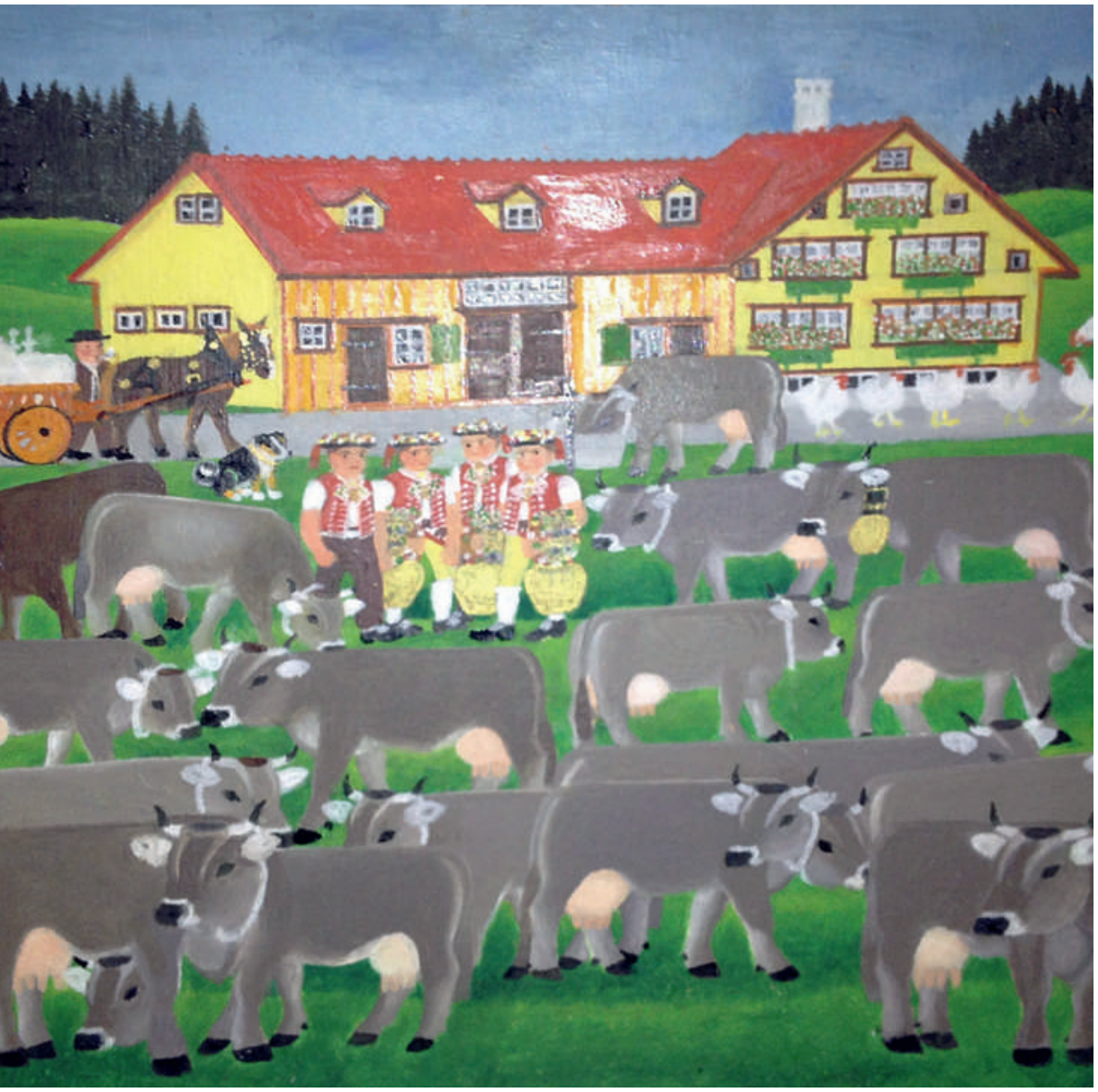

\section{Personen}

- Ein Chefarzt, Chirurg

- Ein Médecin adjoint, Internist mit Praxis im Dorf

- Zwei Assistenzärzte, erste Stelle nach dem Staatsexamen, einer davon der Schreibende

- Eine Oberschwester

- Ein Patient

\section{Anlass}

Chefvisite

\section{Das Geschehen}

Die wöchentliche Chefvisite beginnt im Haupthaus und endet mit dem Besuch des Abs, in dem nur noch vereinzelt Tuberkulose-Patienten untergebracht sind. Der Grossteil der Betten ist mit Patienten belegt, die nach der akuten Phase einer Erkrankung oder nach einer Operation aus verschiedenen Gründen noch einige Tage hospitalisiert bleiben. Es gibt noch keine Rehabilitationskliniken im heutigen Sinn.

Zurück zur Chefvisite des vergangenen Jahrhunderts: Am Ende eines langen Korridors im Abs eine Eckbank, grosser Tisch, grosses Fenster. Ein Patient sitzt im Gegenlicht am Tisch und neigt sich tief über ein Blatt Papier. Er berührt es fast mit der Nase. Beim Nähertreten stellen wir fest, dass der Bauernknecht mittleren Alters etwas malt. Mit feinen Pinselstrichen gestaltet er ein Bild mit einem Bauernhaus mitten in einer Wiese, die von Kühen und einem Appenzellerbläss bevölkert ist, im Hintergrund Hügel und Berge, blauer Himmel.

Rotach der Bauernmaler, das haben wir bis jetzt nicht gewusst. Der Chef spricht ihn an, worauf sich Rotach endlich von seiner Arbeit aufrichtet und das Interesse des Chefs mit einem breiten Lachen aus einem fast zahnlosen Mund quittiert. Das entstehende Bild gefällt dem Chef: «Schön! Wie viel kostet es?» «60 Franken.» «Gut, ich bezahle, wenn es fertig ist.»

Etwas schüchtern geben die beiden Assistenten zu bedenken, dass sie auch Interesse hätten an einer Rotach'schen Bauernmalerei. Der Chef: «Bestellt nur, er bleibt da, bis alles gemalt ist.»

Die Zeiten ändern sich, und wie! 